de la modernidad literaria. Aun después de este alto esfuerzo quedan todavía espacios inexplorados o que requieren estudio a partir de supuestos valorativos por entero diversos. Frente a su ya conocida retórica de schemata, será preciso reconstruir (por ejemplo) su participación en la estilística de la "locura", atendiendo a procedimientos expresivos como la expresión rafez o semiobscena, la fraseología irónica, la metáfora degradadora, los neologismos y plurivalencias semánticas con que había que entretener a un nuevo tipo de público lector que pronto cuajó también en "inmensa minoría". Porque aquella obra, concebida para el goce, no ha dejado nunca de constituir un grave problema de valoración literaria que es como su segunda naturaleza. Guevara comenzó a incorporar ya a sus páginas el proceso creador de éstas, con el estímulo y manipulación lúdica de la curiosidad sobre un autor que se afirmaba a la vez como personaje y sobre unos libros que parecen desmentir o contrariar cuanto pregonan ser. Su lectura "histórica" sólo puede realizarse así como lectura "literaria", atenta a cuestiones internas de concepto, expresión y formas. Lejos de haber cubierto una meta, la crítica guevariana se halla, más que nunca, en una encrucijada que pondrá a todo futuro estudioso ante el compromiso de seguir el ejemplo del propio Guevara en aquello de "cortar algo delgada la pluma".

Harvard University.

Francisco Márquez Villanueva

\title{
EL CASO DEL EPÍGRAFE DESAPARECIDO: CAPÍTULO 43 DE LA EDICIONN PRÍNCIPE DE LA PRIMERA PARTE DEL QUIJOTE
}

$\mathrm{Al}$ capítulo 43 de la edición príncipe de la Primera Parte del Quijote le hace falta su epígrafe. Este vacío fue hasta cierto punto subsanado en el índice que aparece al final del libro, donde se lee: Capitulo quarenta y tres, donde fe quenta la agradable / hiftoria del moço de mulas: con otros eftraños acae- / cimientos en la venta fucedidos. Comiença. Mari- / nero foy de amor. 262 (sigs. ${ }^{* *} 3 \mathrm{y}^{* *} 3 \mathrm{v}$ ). La segunda edición de Cuesta (impresa sólo unas semanas después de la príncipe, ya incluye el epígrafe dentro del texto mismo, donde aparece colocado inmediatamente antes de la canción del mozo de niulas (sig. $\mathrm{Kk5v}$ ). A pesar de esto, aún se dice en el índice, innecesariamente, que el capítulo Comiença. $\mathrm{Ma}$ rine- / ro foy de amor (sig. ${ }^{* *} 3 \mathrm{v}$ ), e incorrectamente se da la página 262, cuando en realidad el epígrafe aparece en la página 261v; pero estos descuidos del cajista son fáciles de corregir y carecen. de importancia. Hay, sin embargo, dos' cuestiones relacionadas con este epígrafe que deben ser aclaradas antes de intentar hacer una edición crítica del Quijote. En este artículo me propongo explicar el porqué de la ausencia del epígrafe en la edición príncipe, y trataré de demostrar que en el manuscrito original de Cervantes el capítulo 43 no comenzaba con la canción 
del enamorado mozo de muías. Mi estudio The compositors of the first and second Madrid editions of "Don Quixote", Part I (Londres, 1975), en el cual aparecen descripciones bibliográficas detalladas de la primera y segunda ediciones madrileñas, y al que en lo sucesivo citaré como Flores, es la base de las conclusiones que presento en este artículo.

Los numerosos errores que se encuentran en los epígrafes de la edición príncipe de la Primera Parte del Quijote pueden todos ser razonados y explicados una vez que se desenreda el laberinto de la creación artística y de la composición tipográfica de la obra. Si se estudian detenidamente estos dos procesos, pronto resulta evidente que la falta del epígrafe que nos ocupa no puede atribuirse ni a un descuido de Cervantes ni a un error del cajista.

Ya se aclaró el proceso gestativo por el cual pasó la Primera Parte del Quijote en mi artículo "Cervantes at work: The writing of Don Qixote, Part I", JHPh, 3 (1979), 135-150. En este estudio se demuestra que Cervantes ya habia superado cuatro complicadas etapas intermedias cuando empezó a escribir el capítulo 43 de la Primera Parte. Aunque Cervantes aún no había acabado con las interpolaciones, el texto ya estaba dividido en capítulos y en partes. Por lo tanto, es casi seguro que Cervantes escribió el epígrafe de este capítulo dentro del texto mismo del manuscrito, y no en el margen superior, como ha de haberlo hecho en el caso de los epígrafes intercalados para los primeros capítulos, y también con los epígrafes intermedios de las novelas interpola. das. El hecho de que el epígrafe apareciera dentro del texto mismo del manuscrito elimina la posibilidad de que el cajista no lo haya visto o de que se lo haya saltado accidentalmente mientras componía su plana. Si la ausencia del epígrafe no se debe ni a un olvido de Cervantes, ni a un descuido del cajista, sólo nos cabe pensar que se debe a una omisión intencional. Para poder explicar esta circunstancia es necesario estudiar cómo se compusieron el pliego doble $\mathrm{Kk}$ (que es donde comienza el capítulo 43), y los pliegos dobles adyacentes: véase la figura 1.

Los cajistas que trabajaron en la edición príncipe de la Primera Parte del Quijote han sido designados con los nombres de cajistas C, D, E

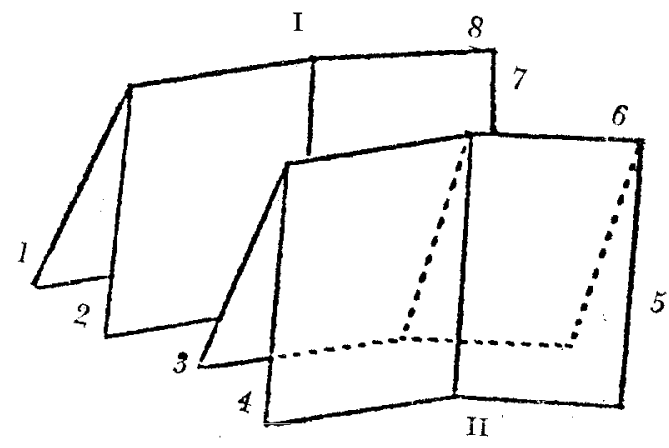

Figura 1. Pliego doble de cuatro típico de la edición príncipe de la Primera Parte del Quijote. 
y F (Flores, pp. 10-12). Tres de estos cajistas compusieron los pliegos que nos interesan en este caso. $\mathbf{E l}$ cajista $\mathbf{C}$ compuso los pliegos Ii y $\mathrm{Mm}$, el cajista $\mathbf{E}$ compuso los pliegos $\mathrm{Kk}$ y $\mathrm{Nn}$, y el cajista $\mathbf{F}$ compuso el pliego Ll.

Ahora bien, en la edición príncipe de la Primera Parte del Quijote hay por lo común treinta y dos líneas por página -excluyendo el titulillo y la línea de reclamo-, y cuando varias páginas de un pliego tienen diferente número de líneas, inmediatamente puede sospecharse que algo fuera de lo normal ocurrió durante la composición de ese pliego (Flores, pp. 13-16).

De los pliegos que necesitamos examinar en este estudio, los pliegos Ll y Nn no presentan ninguna página con un número irregular de líneas, porque los cajistas aparentemente terminaron estos pliegos antes de que se repartiera copia para los pliegos $\mathrm{Mm}$ y Oo, y acabaron de componer donde les convino. Los pliegos Ii y Mm tienen, por otra parte, trece páginas irregulares entre los dos (las sigs. Ii5v y li6 tienen veintinueve lineas; las sigs. Ii3, Ii3v, Ii4, Ii4v, Ii5 e Ji6v tienen treinta líneas; las sigs. Ii7 e li7v tienen treinta y una líneas; las sigs. Mm4v, Mm5 y Mm5v tienen treinta y tres líneas, y la sig. Mm2 tiene 30 líneas). Esto implica que los pliegos li y $\mathrm{Mm}$ fueron compuestos concurrentemente con otros pliegos (Ii-Kk-Ll; y Mm-Nn), y que el cajista $\mathbf{C}$ tuvo que hacer caso omiso del número común de líneas por página, porqne cuando se le acabó la copia le hacían falta veinte líneas para completar el pliego li con planas regulares, y porque le sobraron trece líneas al acabar de componer el pliego $\mathrm{Mm}$ ( $\mathrm{C}$ absorbió diez líneas con abreviaturas y tres con líneas extras). Como es muy probable que ya hubieran entrado en prensa algunas de las hojas de los pliegos $\mathrm{Kk}$ y $\mathrm{Nn}$, el cajista $\mathrm{C}$ se vio obligado a absorber el sobrante y a distribuir el faltante en sus propias pianas; y, en consecuencia, terminó con catorce planas irregulares en estos dos pliegos. Es pues, obvio, que la composición simultánea de pliegos contiguos ha dejado su huella en la apariencia misma de los pliegos porque, les faltara o les sobrara copia a los cajistas, éstos generalmente se veían obligados a hacer caber todo el texto de la tarea en las dieciséis planas por pliego que le correspondían a cada uno. Las diferencias entre los números de líneas por página y las variaciones bruscas en el número de abreviaturas son, por lo tanto, muy importantes, ya que pueden ayudarnos a discernir cuándo, y cuándo no, se repartió copia para composición simultánea. Lo extraño, entonces, no es que los pliegos $\mathrm{Ii}$ y $\mathrm{Mm}$ presenten anomalías, sino que el pliego Kk no tenga ninguna página irregular a pesar de haberse compuesto simultáneamente con los pliegos Ii y Ll. Esta aparente contradicción se desvanece, sin embargo, cuando se conocen las peculiaridades tipográficas que caracterizan la composición del cajista $\mathrm{E}$.

Una de las características del cajista $\mathbf{E}$ era que estaba acostumbrado a componer planas de treinta y tres líneas (once componedores de tres líneas de letra atanasia) en vez de planas de treinta y dos (ocho componedores de cuatro líneas de letra atanasia), como las que se necesitaban para la edición príncipe de la Primera Parte del Quijote. Prueba de esto 
es que cuando $\mathrm{E}$ compuso el pliego del prólogo (II), que fue el último pliego doble que se compuso, volvió a las planas de treinta y tres líneas simplemente por hábito. También se refleja esta costumbre en el hecho de que en cuatro ocasiones el cajista $\mathrm{E}$ automáticamente mezcló componedores de tres líneas con los de cuatro, y acabó con cuatro planas irregulares (las sigs. 18, $\mathrm{R} 3 \mathrm{v}, \mathrm{R} 4$ y $\mathrm{Bb} 8$ tienen treinta y una líneas por página). Estas anomalías no pueden achacarse a composición concurrente como las de los pliegos Ii y $\mathrm{Mm}$, porque los cajistas no empezaron a componer sus tareas simultáneamente sino hasta que llegaron a los pliegos X-Y-Z. La plana irregular del pliego $\mathrm{Bb}$ también ha de haber sido una anomalía accidental porque el cajista $\mathrm{E}$ era incapaz de introducir una irregularidad que podía haberse evitado simplemente metiendo una regleta más entre el texto y alguno de los poemas que aparecen en este pliego. Es evidente que el hábito de componer planas de treinta y tres líneas estaba bien arraigado en el cajista $\mathbf{E}$, pero también es obvio que cuando se tenía que componer un trabajo con planas con un número diferente de líneas, $\mathrm{E}$ se mostraba cuidadoso y era capaz de cualquier cosa con tal de evitar una plana irregular. La única vez que $\mathrm{E}$ aceptó planas irregulares fue en el pliego $\mathrm{Y}$ (las sigs. Yl, Ylv, Y2 e Y2v tienen treinta y tres líneas), pero esto se debió a que el cajista $F$ se encontró que tenía un sobrante de diez líneas cuando acabó de componer la copia del pliego $\mathrm{X}$, y que no podía absorber este sobrante en sus propias planas (tres caras de las hojas del pliego $\mathrm{X}$ ya habían entrado en prensa), así que se lo pasó a E. El cajista E no tuvo otro remedio que aceptar el sobrante de $F$, pero aún aquí mostró su determinación de evitar cuanto fuera posible planas irregulares, y de las diez líneas que le pasó $\mathrm{F}$ sólo incorporó cuatro directamente. Las otras seis líneas las tuvo que absorber metiendo ciento setenta abreviaturas adicionales en las cuatro planas que aún tenía disponibles, para lo cual tuvo que alterar, ajustar y volver a componer veintenas de líneas a todo lo largo de estas páginas (Flores, pp. 14-16).

Al cajista E, sin embargo, no le gustaba usar abreviaturas. Generalmente usaba un promedio de tres o cuatro abreviaturas por plana, pero en las últimas treinta y siete líneas del pliego $\mathrm{Kk}$ usó treinta y dos abreviaturas. E empezó usando muchas abreviaturas en los primeros pliegos que compuso ( $\mathrm{I}, \mathrm{K}, \mathrm{M}$ y $\mathrm{N}$ ) porque no estaba familiarizado ni con la caligrafía ni con la ortografía de Cervantes y componía lo que veía, no lo que leía (Flores, p. 81); pero una vez acostumbrado al manuscrito empezó a usar poquísimas abreviaturas, y en las pocas ocasiones en que usó más abreviaturas de lo común lo hizo en planas aisladas, al azar y sin ninguna lógica aparente. Así pues, el número poco común de abreviaturas usadas en las últimas líneas del pliego $\mathrm{Kk}$ ya es en sí revelador. Aún más, el hecho de que estas abreviaturas aparezcan precisamente al final de la tarea es indicio claro de que poco antes de acabar el pliego, el cajista se dio cuenta de que iba a sobrarle copia y que inmediatamente empezó a usar más abreviaturas de lo normal; pero poco le sirvió esto, porque sólo pudo ahorrar una línea y media en el proceso y de todas maneras acabó con un sobrante. 
Ahora bien, otra característica del cajista E era que componía más lentamente que los otros oficiales que trabajaron en la primera edición de la Primera Parte del Quijote, y esta lentitud tendría repercusiones no solamente en la edición príncipe, sino también en la segunda edición de Cuesta (Flores, pp. 41-68). Aunque los cajistas $\mathrm{E}$ y F formaban un equipo, los dos levantaban letra a diferentes velocidades. El cajista $\mathrm{E}$ era más lento, y parece que $\mathrm{F}$ era el más rápido de los cuatro cajistas de la primera edición. De esta diferencia entre los cajistas resultó que cuando $\mathrm{E}$ acabó de componer la copia del pliego $\mathbf{K k}$, probablemente se encontró con que los cajistas $\mathrm{C}$ y $\mathrm{F}$ ya hacía tiempo que habían acabado con los pliegos li y Ll, y que algunas de las caras de las hojas de estos pliegos ya se habían impreso y otras estaban en prensa. Así pues, el cajista $E$ no pudo pedir a ninguno de los otros dos cajistas que absorbiera las líneas de tipo que le habian sobrado a él. Como parece que ninguna de las caras de las hojas del pliego Kk habían entrado en prensa (véase la figura 2), el cajista $\mathrm{E}$ estaba en completa libertad para mover parte de la composición de una plana a otra y repartir el sobrante entre las diferentes planas del pliego.

Figura 2. Formas para pliego doble de cuarto ordenadas según se completaban

Formas para la hoja interior
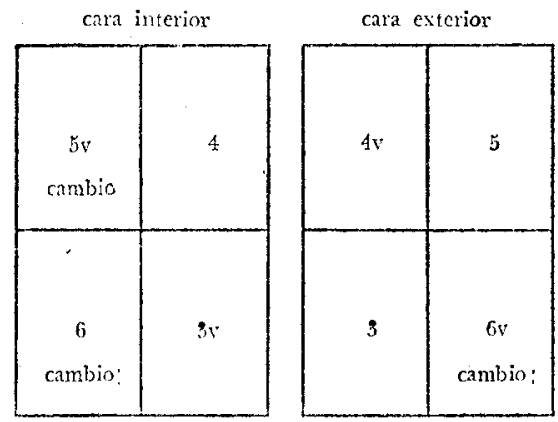

Formas para lit hoja extcrios
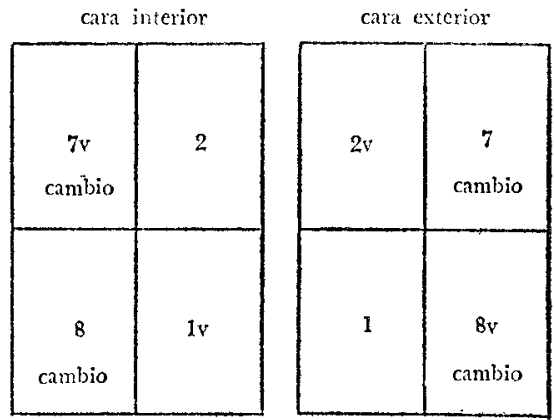

Estos esquemas representan planas de tipo y formas tipográficas. Nótese que todas las formas sufrieron cambios, así que lo más probable es que las planas hayan estado ajustadas pero no impuestas.

Si el sobrante hubiera sido de cuatro o de cinco líneas hubiera sido muy fácil absorberlo. El cajista hubiera podido sacar de la composición hasta cinco o seis regletas sin desdecir la apariencia del texto, simplemente cerrando los espacios que había antes y después de los epígrafes y de los poemas. Sin embargo, parece que el sobrante era de entre ocho y diez líneas, y que el cajista tuvo que considerar otras posibilidades. La manera más fácil de salir de este aprieto hubiera sido cerrando algunos espacios y aumentando una línea en las últimas planas del pliego hasta que se hubiera acabado con el sobrante, pero ya se ha visto la aversión que tenía $\mathrm{E}$ a las planas con un número irregular de líneas. Otras solu- 
ciones prácticas hubieran sido: 1) cerrar espacios y distribuir y componer de nuevo dos o tres planas para absorber parte del sobrante con abreviaturas, o 2) cerrar espacios, sacar los poemas que aparecen en el pliego, y volver a componerlos usando letra cursiva de lectura en vez de atanasia (véanse las signaturas $\mathrm{Kk} 6, \mathrm{Kk} 7$ y $\mathrm{Kk} 7 \mathrm{v}$ de la primera edición). Cualquiera de estas soluciones hubiera alcanzado el efecto deseado, pero ambas requerían tiempo y parece que en esta etapa de la impresión éste era el único lujo que no podían darse los cajistas. La impresión iba avanzando a un paso acelerado (Flores, p. 81), y como el cajista $\mathbf{E}$ era ya de por sí lento, no podía detenerse a distribuir y recomponer lo ya hecho. Así que hizo una barbaridad. Sacó de la composición el epígrafe del capítulo 43, hilvanó el texto, y desplazó entre ocho y diez líneas de plana en plana.

El epígrafe, sin embargo, no estaba originalmente en la plana Kk6, como se dice incorrectamente en el índice de la edición príncipe, puesto que entonces su desaparición no habría tenido ningún objeto práctico. Si el capítulo 43 hubiera dado principio con la canción del mozo de mulas, el cajista sólo se habría ahorrado cuatro líneas sacando el epígrafe de esta posición, ya que no podía disponer de los espacios que había entre el texto y el epígrafe porque los necesitaba para separar la canción del texto. Si éste hubiera sido el caso, la solución tan tajante que el cajista tomó resultaría innecesaria y absurda, puesto que, como ya se ha visto, podría haberse ahorrado ese númeo de líneas sin tener que tocar para nada el epígrafe. Pero si no comenzaba el capítulo con la canción, ¿dónde empezaba?

- Afortunadamente, hay, además de.la evidencia tipográfica, dos carác terísticas textuales que nos dan la respuesta. En primer lugar, el texto mismo del epígrafe sugiere que el capítulo comenzaba al principio de la historia del mozo de mulas, es decir, varias líneas antes de la canción, ya que las primeras palabras del epígrafe son: "donde fe quenta la agradable / hiftoria del moço de mulas". Verdad es que en la Primera Parte del Quijote hay varios errores de discordancia entre epígrafes y contenido textual, pero debe recordarse que Cervantes incurrió en estos errores antes de llegar al capítulo 43, porque cuando intercaló la historia del mozo de muías ya dividía los capítulos y redactabà los epígrafes conforme iba escribiéndolos, y no como un expediente tardío. Así que la discordancia entre este epígrafe y lo que le sigue no puede achacarse a un descuido de Cervantes. Si el capítulo hubiera empezado con la canción, es probable que Cervantes hubiera redactado el principio del epígrafe de otra manera, tal vez, "donde se pone la canción de mozo de mulas.", como lo hizo en el epígrafe del capítulo catorce (Cap. XIIII. Donde fe ponen los verfos defefperados del / difunto paftor, con otros no efperados fuceffos, sig. G4v), o quizá, "donde se prosigue la historia del mozo de mulas", como lo hizo en el epígrafe que encabeza el primer soneto del capítulo cuarenta (Cap. XL. Donde fe profigue la hiftoria del cautiuo, sig. Gg3). Basta cotéjar algunos de ios elementos técnico-formales del Quijote para darse cuenta de que a estas alturas Cervantes todavía no alcanzaba la fluidez, variedad y originalidad de la Segunda Par- 
te en lo que se refiere a la redacción de epígrafes y fórmulas de transición. $Y$ es precisamente la repetición de una de las fórmulas transicionales la que demarca el final del capítulo cuarenta y dos y el principio del cuarenta y tres.

Cervantes termina los capítulos 18, 19, 21, 23, 27 y 37 de la Primera Parte con las siguientes palabras:

"lo que fe dira en el figuiente capitulo". (sigs. K8, L4v y N4v)

"lo que fe dira adelante". (sig. P2v)

"lo que fe dira en la quarta parte de efta narracion". (sig. T4)

"como ahora dire". (sig. Ff3)

Este tipo de construcción se repite sólo una vez más èn la Primera Parte, y aparece precisamente en la página $26 \mathrm{lv}$, donde se lee:

Solo Sancho Pança fe defefperaua, con la tardança del recogimiento, y folo el Se acomodò mejor que todos, echandofe fobre los aparejos de fu jumento, que le coftaron tan caros, como adelante fe dira. Recogidas pues las damas en fu eftancia, y los demas acomodadofe, como menos mal pudieron, don Quixote fe falio fuera de la venta, a hazer la centinela del caftillo, como lo auia prometido. (Líneas 10 a la 17 de la signatura Kk5v).

Lo que es más revelador es el hecho de que si se reacomodan estas dos oraciones en capítulos separados, tal y como las hubiera compuesto el cajista $\mathrm{E}$, todas las diferentes partes coinciden hasta el último milimetro. Es indudable, pues, que el cajista decidió incorporar el sobrante que tenía en sus propias pianas, y que lo hizo a expensas del epígrafe de la plana $\mathrm{Kk} 5 \mathrm{v}$; véase la figura 3 .

Figura 3. Planas ajustadas del pliego $\mathrm{Kk}$

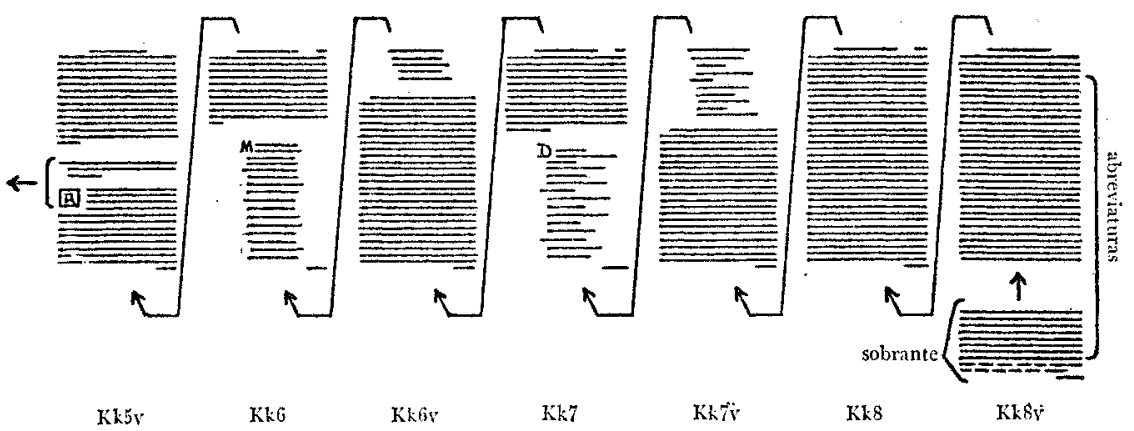

En la gran mayoría de los principios de capítulo de la primera, segunda y tercera edición de Cuesta de la Primera Parte del Quijote se usaron los tacos de un alfabeto ornamental que la imprenta habia adquirido en el año 1587; así que es casi seguro que el cajista $E$ haya usado la " $R$ " de este alfabeto para principiar el capítulo 43, y que haya compuesto la primera palabra del capítulo con letra versal, como era su 


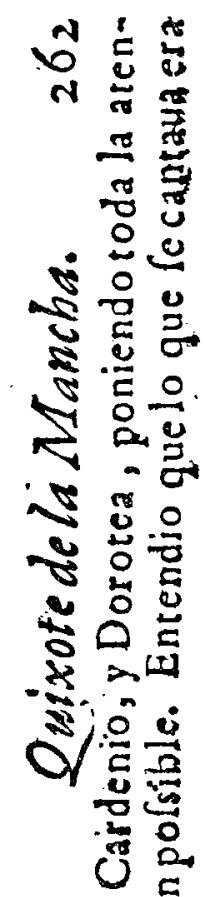

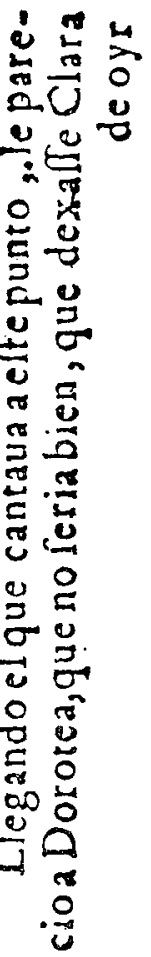

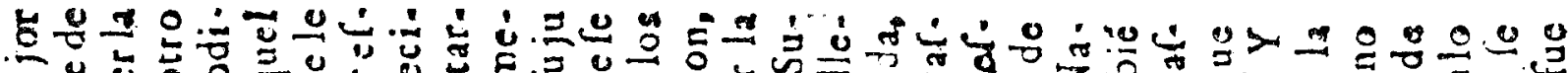

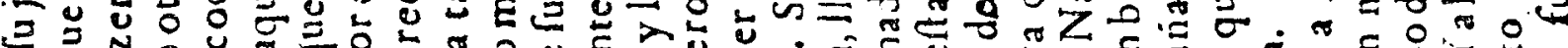
西 숭

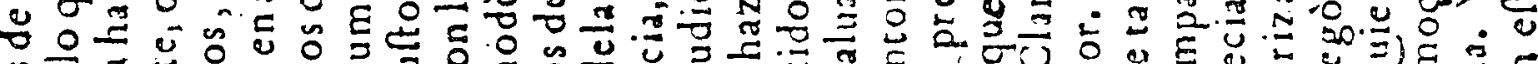

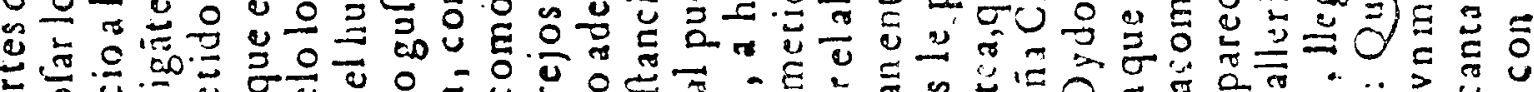
大 จ थ

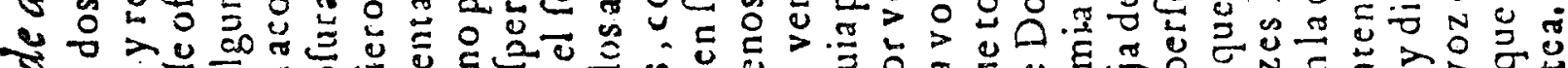

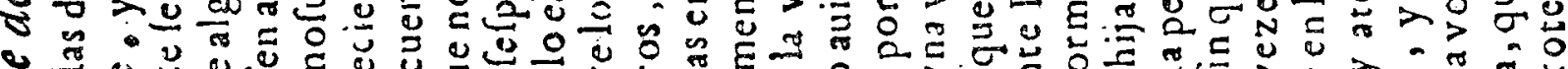

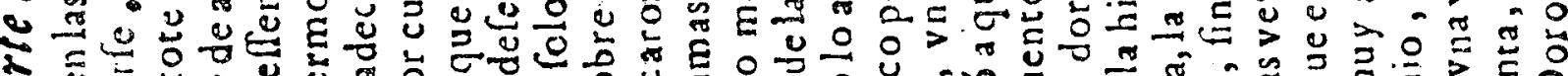

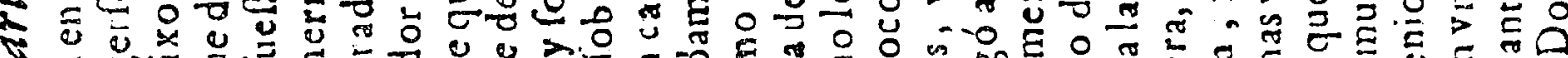
Q *

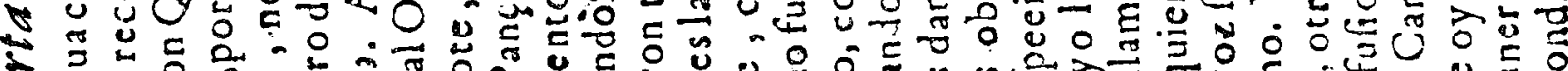

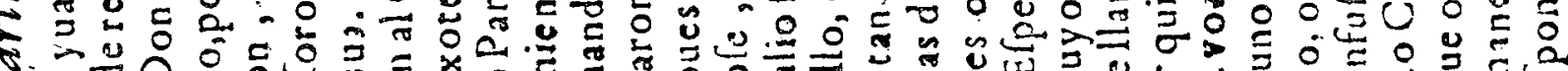

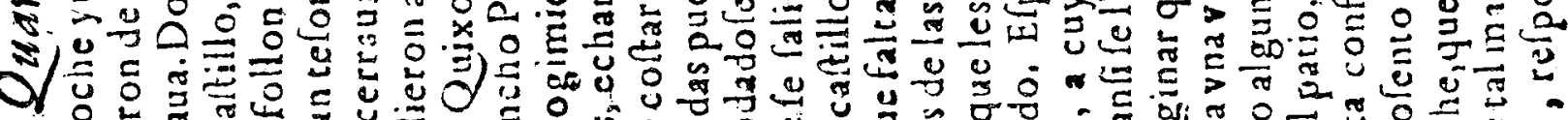
뉴

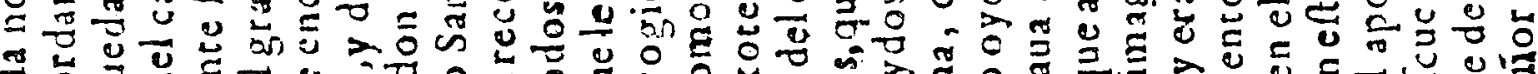

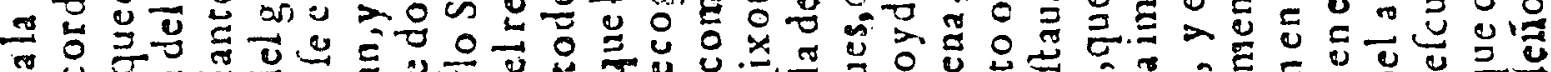
শu

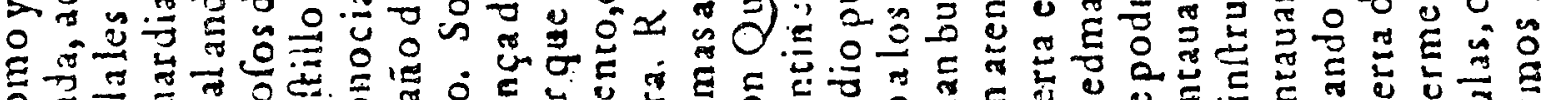

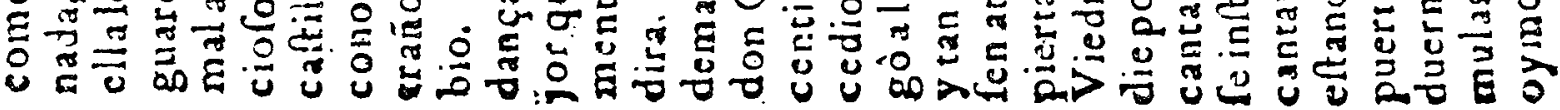



N

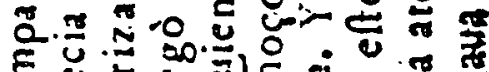

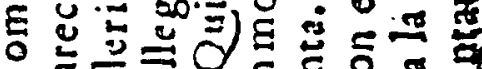
$020=0$ 둥

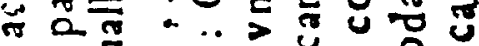

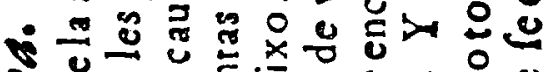

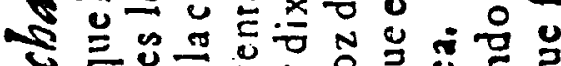

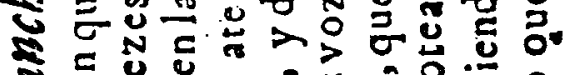

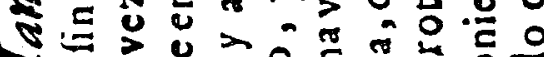
$\triangle \sim \sim 2$ 을

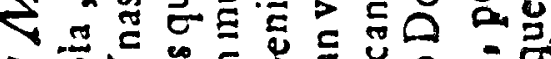

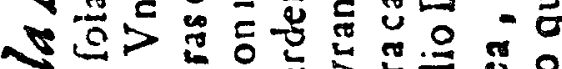

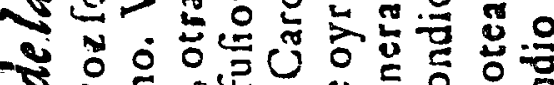

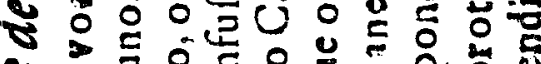

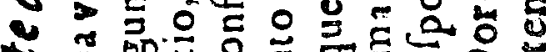
$\Rightarrow$ E

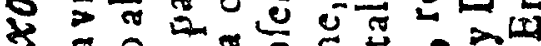
- 市, 过

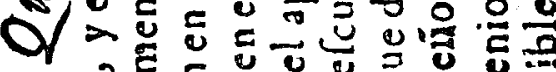
$\approx 55 \%$ 눙

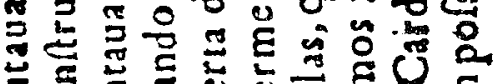

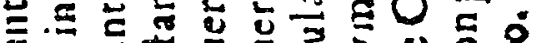
Uิ

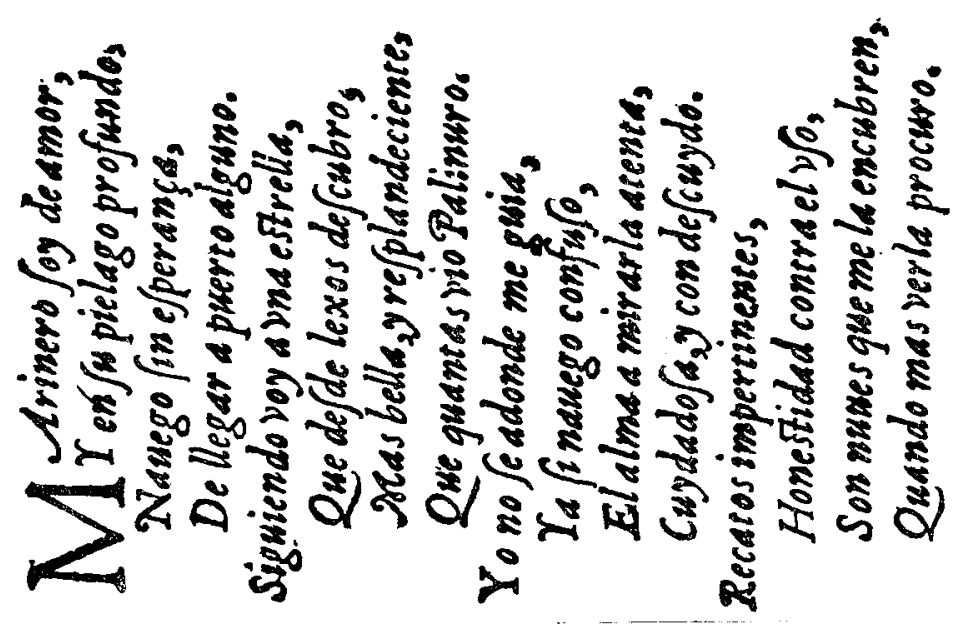


costumbre (véanse los principios del prólogo, de la carta de don Quijote a Dulcinea, sig. R1, y de los capítulos 17-14, 18-K1v, 19-K8, 21-M5v, 22N4v, 26-R3，27-R8v, 29-V6v, 31-Y4, 34-Bb3, 38-Ff3, 39-Ff6, 42-Kk1 y 47-Nn4; cuando la primera palabra del capítulo era muy pequeña el cajista también componía la segunda palabra con tipos de caja alta). Si reconstruimos el epígrafe y las cuatro primeras líneas del capítulo 43 siguiendo las costumbres inalterables del cajista $\mathrm{E}$, nos encontramos que las piezas del rompecabezas no sólo encajan bien, sino que lo hacen con una precisión asombrosa; véanse las láminas 1 (estado original) y 2 (estado actual, ejemplar G.10170 The National Library, Londres) .

En la reconstrución de la lámina 1 he usado íntegro el epígrafe que aparece en la segunda edición de Cuesta (ejemplar G.10171 The National Library) porque fue compuesto por el mismo cajista que levantó letra para el pliego Kk de la edición príncipe, y porque éste usó la misma caja de letra cursiva de texto en ambas ediciones. Nótese que al reacomodar las líneas solamente me he permitido la libertad de agregar el taco, de poner con letra mayúscula la primera palabra del texto, y de separar y dividir en cinco líneas las tres que ahora aparecen unidas a la mitad de la página. Como no hay ningún capítulo que comience con la letra " $R$ " en ninguna de las ediciones madrileñas del Quijote, la fotografía del taco proviene de Antonio de Guevara, Epistolas familiares, Viuda de Pedro Madrigal, Madrid, 1595, sig. $\$ 5 \mathrm{v}$, ejemplar Acton.d.49.318 de la Biblioteca de la Universidad de Cambridge. Moví sólo ocho líneas de la página $\mathrm{Kk} 5 \mathrm{v}$ a la página $\mathrm{Kk6}$ para conservar cuanto fuera posible los mismos espacios que hay entre el epígrafe y el texto de la segunda edición, aunque para hacer corresponder las planas tuve que dar un poco más de espacio entre el epígrafe y el texto del capítulo 43; sin embargo, es muy posible que el sobrante del cajista $\mathrm{E}$ haya sido mayor de ocho líneas.

A pesar de que no he tocado ni alterado de manera alguna el resto del texto, y he conservado idénticos los espaciós entre las palabras, puede verse que la exactitud de la alineación es sorprendente. Las únicas "irregularidades" aparecen en la segunda línea del capítulo, donde hace falta un espacio entre las palabras "los" y "demas", y en la tercera línea, donde hace falta un guión de separación después de las sílabas "Quixo". Pero éstas, en realidad, no son irregularidades. Cuando el cajista separó. en dos líneas las palabras "los" y "demas" tuvo, claro está, que eliminar el espacio intermedio, pero como lo necesitaba para realinear lo metió, como era su costumbre, entre una palabra (acomodadofe) y la coma que le sigue; véanse, por ejemplo, las líneas 4 y 10 del nuevo capítulo - "venta ", a" y "eftaua , a". Es natural, pues, que el espacio aparezca corrido cuando se regresan las líneas a su posición original. Asi mismo, cuando el cajista juntó las sílabas "Quixo" y "te" tuvo que omitir el guión, y por eso ahora hace falta en la reconstrucción de la plana. En otras palabras, todas las piezas encajan perfectamente en su lugar. De este hecho puede concluirse que la evidencia tipográfica y textual pre sentada en este artículo no puede atribuirse a mera coincidencia.

Quitando el epígrafe de la plana Kk5̌v el cajista se ahorró cuatro lí 
neas de letra atanasia (tres de letra de texto), sacando las regletas se ahorró entre tres y cinco líneas más, y suprimiendo el taco y uniendo el texto de los dos capítulos se ahorró otras dos líneas. En el hueco que quedó al pie de la plana el cajista acomodó entre ocho y diez líneas de la plana Kk6. Después, reajustó todas las otras planas e incorporó, en la última plana del pliego, el sobrante que le había quedado al terminar su tarea.

La razón por la que el cajista cambió, o hizo cambiar en el índice la posición original del epígrafe es obvia. Al lector le parece muy natural que el capítulo termine y dé principio con una separación formal, mientras que hubiera sido una torpeza que se hubiera dicho en el índice que el capítulo comenzaba a la mitad de una línea y sin división formal de ninguna clase. Tan es esto verdad, que han pasado más de tres siglos y medio sin que nadie sospechara que originalmente el capítulo 43 de la Primera Parte del Quijote principiaba antes de la canción del mozo de muías, y no con ella. Sin embargo, la evidencia tipográfica y textual aducida aquí es incontrovertible. Cuando el cajista E terminó de componer su tarea para el pliego $\mathrm{Kk}$ se encontró que tenía un sobrante y que tenía que absorberlo en sus propias planas. Como no tenía tiempo para recomponer sus planas y absorber el sobrante con abreviaturas, como le hubiera gustado hacerlo, y como tenía una verdadera fobia a las planas con un número irregular de líneas, el cajista $\mathrm{E}$ hizo la barrabasada de sacar un epígrafe de la plana $\mathrm{Kk} 5 \mathrm{v}$, de juntar el texto de los dos capítulos, y de decir, o hacer decir en el índice, que el capítulo 43 comenzaba con la canción "Marinero soy de amor". Esta actitud irresponsable del cajista $\mathrm{E}$ demuestra, una vez más, que los cajistas de la edición príncipe de la Primera Parte del Quijote seguían o alteraban su copia según les convenía, y que sus acciones dependían más de sus hábitos profesionales que de su copia, o de reglas impuestas por la imprenta o por el autor de las obras que componía *.

University of British Columbia.

R. M. Flores

\section{MATEO ALEMAN Y SUS FUENTES LITERARIAS}

Se ha querido ver una combinación de experiencia vivida y de converso por un lado, y lecturas varias - sobre todo ascéticas- por otro, como génesis del Guzmán de Alfarache. Se supone que la experiencia vital anima los resentimientos, las descripciones de la realidad sevillana, la vida de galeote, etc. Las lecturas pías son consideradas la fuente de muchos sermones. E. Cros ha hecho ver la importancia de fuentes como los Mondi de Doni y el Diálogo de los pajes de Diego de Hermosilla ${ }^{1}$.

* Las conclusiones de este artículo se presentaron en el VI Congreso de la Asoción Internacional de Hispanistas, Toronto, 1977.

1 Edmond Cros, Protée et le guex, Paris, 1967, pp. 337-350. 